\title{
A message from the Editor in Chief
}

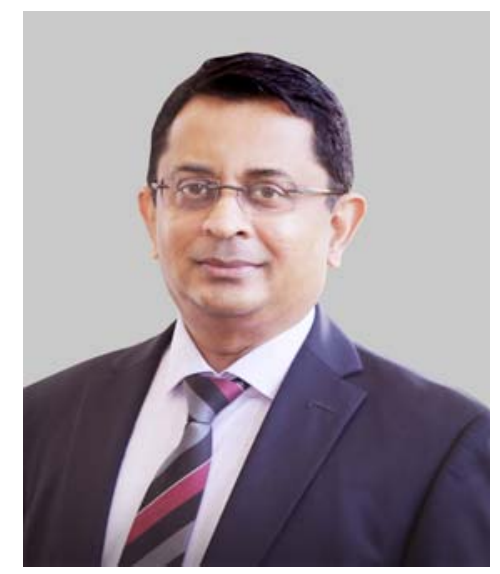

Many things have changed since I last edited SLJOG in December 2012, yet many sadly remain the same.

The COVID-19 pandemic rolls heavily on our lives, cases continue to rise although we all wanted to hear "Now that the pandemic is over...".

In the face of all these difficulties I at SLJOG editorial office remain ever grateful for the hard work provided by the authors, editorial board members to bring you the September edition of SLOG.

We are always on the lookout for interesting articles and always grateful to those who volunteer their time to peer review our papers. Without them, we would not have a journal.

In this quarter's Journal, we have articles covering a wide range of topics in obstetrics and gynaecology.

Although we have published COVID-19 specific article as the leading article, one must understand rapidly changing disease pattern, treatment options and post pandemic crisis is still at large without proper consensus.

The way forward for those who wanting to submit articles to SLOG, Instructions for Authors are found on the SLOG web page https://sljog.sljol.info/.

To have a greater chance of publication, please consider the following. First, it should be primarily a review article rather than a case report, study or personal opinion; second, it should not duplicate what is already available; third, make sure the authors include an appropriate experts with an informed overview of the topic; and finally, think about what the audience wants to read more than what you want to write.

Finally, it is my humble duty to acknowledge and extend my profound gratitude to Professor Rukshan Fernandopulle, the outgoing Editor in Chief of SLJOG who has done a tremendous job to improve the Journal. I acknowledge the editorial Secretary Ms. Piumi Nayakarathna and the Ananda Press team for their outstanding work in order to make this a success.

\section{Dr. Sanath Lanerolle}

(MBBS, MS, FRCOG, FSLCOG, D(OBS)RCPI, FIAOG, FMAS, FICS)

Consultant Obstetrician and Gynaecologist, Castle Street Hospital for Women, Colombo 08.

\section{Editor in Chief,}

SLJOG

Email: slanerolle@hotmail.com

DOI: http://doi.org/10.4038/sljog.v43i3.8012 